\title{
Management of Adverse Events During Rucaparib Treatment for Relapsed Ovarian Cancer: A Review of Published Studies and Practical Guidance
}

\author{
Domenica Lorusso ${ }^{1}$ • Jesús García-Donas ${ }^{2}$ · Jalid Sehouli ${ }^{3}$. Florence Joly ${ }^{4}$
}

Published online: 3 June 2020

(c) The Author(s) 2020

\begin{abstract}
The poly(ADP-ribose) polymerase inhibitor rucaparib is approved as monotherapy in the treatment and maintenance settings for women with relapsed ovarian cancer in the European Union and the United States. We review the safety profile of rucaparib in both settings and provide recommendations for the clinical management of the main adverse events (AEs) that may occur during rucaparib treatment. We searched PubMed and congress proceedings for safety data on oral rucaparib monotherapy (600 mg twice daily) from clinical trials involving patients with relapsed ovarian cancer. AE management guidance was developed from clinical trial protocols, rucaparib prescribing information, oncology association guidelines, and author experience. The most frequent any-grade treatment-emergent AEs (TEAEs) included gastrointestinal symptoms, asthenia/fatigue, dysgeusia, anemia/decreased hemoglobin, and increased alanine/aspartate aminotransferase. Across clinical trials, $61.8 \%$ of patients had one or more grade 3 or higher TEAEs. Clinicians should employ close follow-up for TEAEs, particularly early in treatment, and educate patients about expected TEAEs and methods for their monitoring and management (e.g., antiemetics for nausea/vomiting, transfusions for hematologic TEAEs, or dose interruptions/reductions for moderate/severe TEAEs). Overall, $16.2 \%$ of patients discontinued rucaparib due to TEAEs. Management of AEs that may occur during rucaparib treatment is crucial for patients to obtain optimal clinical benefit by remaining on therapy and to avoid their detrimental impact on quality of life.
\end{abstract}

\section{Introduction}

Standard treatment for patients with advanced ovarian cancer includes surgery followed by platinum-based chemotherapy $[1,2]$; however, the majority of patients relapse and

Jalid Sehouli and Florence Joly contributed equally to this work.

Domenica Lorusso

domenica.lorusso@policlinicogemelli.it

1 Gynecologic Oncology Unit, Fondazione Policlinico Universitario A. Gemelli IRCCS, Largo Agostino Gemelli 8, 00168 Rome, Italy

2 Medical Oncology Service, HM Hospitales-Centro Integral Oncológico Hospital de Madrid Clara Campal, Madrid, Spain

3 Department of Gynecology and Oncological Surgery, Charité University Medicine of Berlin and NOGGO, Berlin, Germany

4 Medical Oncology Department, Centre François Baclesse, Université Unicaen and GINECO, Caen, France

\section{Key Points}

Clinicians and patients should be informed about the safety profile of rucaparib and methods to manage treatment-emergent adverse events (TEAEs) during rucaparib therapy.

The TEAEs that occur during rucaparib therapy are easily managed in accordance with the rucaparib prescribing information, as well as guidelines from oncology societies and working groups.

require subsequent treatment $[2,3]$ with a second line of platinum-based therapy in the case of late relapse (generally at least 6 months after the end of the previous line of platinum-based therapy) [1,2]. Relapsed ovarian cancer is an incurable disease. Nevertheless, in recent years, targeted therapies, such as antivascular endothelial growth factor therapy (bevacizumab) and poly(ADP-ribose) polymerase (PARP) inhibitors (rucaparib, olaparib, and niraparib) have 
become available for women with relapsed ovarian, fallopian, or peritoneal cancer. PARP inhibitors have demonstrated efficacy in patients both with or without a deleterious $B R C A 1$ or BRCA2 (BRCA) mutation.

Rucaparib, one of the newest additions to the treatment landscape for relapsed ovarian cancer, inhibits PARP1, PARP2, and PARP3, and prevents the repair of singlestrand breaks in DNA [4]. Unrepaired single-strand breaks lead to double-strand breaks in DNA, which is ultimately lethal in cells with homologous recombination deficiency (e.g., cells with a deleterious $B R C A$ mutation) $[5,6]$. In two clinical trials in the treatment setting, Study 10 (CO338-010; NCT01482715) [7] and ARIEL2 (CO-338-017; NCT01891344) [8], rucaparib monotherapy was shown to have antitumor activity in patients with relapsed epithelial ovarian, fallopian tube, or primary peritoneal cancer with a deleterious BRCA mutation (germline in Study 10; germline or somatic in ARIEL2) who had received two or more prior chemotherapy regimens [7-10]. In the randomized, phase III ARIEL3 trial (CO-338-014; NCT01968213), rucaparib maintenance treatment after response to platinum-based chemotherapy significantly improved progression-free survival (PFS) versus placebo in all primary analysis groups of patients with platinum-sensitive relapsed ovarian cancer [11]. On the basis of the results of these studies, rucaparib monotherapy is approved in the treatment setting for women with relapsed, $B R C A$-mutant, high-grade epithelial ovarian cancer who have received at least two lines of platinumbased chemotherapy in both the European Union (EU) and the United States (US) [12, 13]. Rucaparib is also approved in both the EU and the US in the maintenance setting for women with relapsed ovarian cancer following a response to platinum-based chemotherapy regardless of $B R C A$ status $[12,13]$.

With the addition of rucaparib and other targeted therapies to the treatment landscape for relapsed ovarian cancer, patient and clinician education on the range of options is crucial, as these therapies can be used in specific settings (treatment and/or maintenance) and each of the agents has a unique efficacy and safety profile [14]. For instance, clinicians should help patients understand differences between the treatment and maintenance settings. In the treatment setting, an agent is delivered after evidence of disease progression. A patient may progress while receiving chemotherapy, or shortly thereafter, and may immediately switch to a new agent. For some patients, disease progression may occur some time after completion of chemotherapy, allowing time for recovery from chemotherapy-related adverse events (AEs) and leading to quality-of-life improvements before initiating a new agent. In the maintenance setting, an agent is delivered to patients who are in response to current chemotherapy with the intention of prolonging PFS and the time to the next medical intervention without detrimentally affecting patient quality of life. Clinicians and patients should also understand the efficacy of these newer, targeted agents across their various approved settings. Furthermore, each agent has a distinct safety profile $[14,15]$, and this, as well as other factors (Table 1), should be considered as part of the treatment decision-making process and clinical management of patients. Notably, a recent North-Eastern German Society of Gynaecological Oncology (NOGGO) survey on the perspectives and expectations of patients with ovarian cancer regarding maintenance therapies indicates that patients may have difficulty differentiating between adverse effects that could be attributed to maintenance treatment versus those from previous therapies, highlighting the importance of educating patients on possible adverse effects of maintenance therapies [16].

In this article, we review the available literature regarding the safety profile of rucaparib in both the monotherapy treatment and maintenance settings. We also offer guidance regarding management of the main treatment-emergent AEs (TEAEs) observed with rucaparib, based on prescribing information, clinical trial protocols, evidence-based

Table 1 Factors that may influence the treatment decision-making process in relapsed ovarian cancer

\begin{tabular}{|c|c|}
\hline Disease-related factors & Patient-related factors \\
\hline Current disease symptoms & General and functional status \\
\hline Tumor pattern & Relevant comorbidities or comedication \\
\hline Tumor biology (e.g. BRCA mutant) & Ability to tolerate oral medications \\
\hline $\begin{array}{l}\text { Duration of therapy-free and/or progression-free interval } \\
\text { (e.g. platinum refractory, resistant, or sensitive) }\end{array}$ & Motivation and preferences of the patient \\
\hline Factors associated with prior treatments & Factors associated with subsequent treatment \\
\hline Quality and results of prior surgical and medical therapies & Type of treatment (e.g. chemotherapy, targeted agent) \\
\hline Adverse events and complications from previous therapies & Potential persistent adverse events \\
\hline Previous therapy with bevacizumab & Resources to overcome complications \\
\hline
\end{tabular}

Adapted from the treatment decision algorithm utilized at Charité University Medicine of Berlin 
guidelines from oncology societies and working groups, and the clinical experience of physicians from several different European institutions.

\section{Methods and Search Results}

To identify publications containing safety data from clinical trials of oral rucaparib as a single agent in the treatment or maintenance setting conducted in patients with relapsed ovarian cancer, we searched PubMed up to 11 March 2020, using the following search string: "(rucaparib AND ovarian cancer AND (adverse event OR safety OR tolerability) NOT combination) AND clinical trial NOT review[Filter]".
No date restrictions were applied. Only studies that reported on safety at the recommended starting dose of oral rucaparib $600 \mathrm{mg}$ twice daily were included for further examination; review articles were excluded.

Our PubMed search returned seven publications (Fig. 1): Drew et al. [17], Kristeleit et al. [7], Swisher et al. [8], Balasubramaniam et al. [18], Oza et al. [9], Coleman et al. [11], and Kristeleit et al. [10]. The publication by Drew et al. [17] was excluded because the reported safety data were pooled across patients who received different doses and/or formulations of rucaparib. Balasubramaniam et al. [18] cited data already found in Swisher et al. [8], and was therefore also excluded. Oza et al. [9] and Kristeleit et al. [10] reported integrated efficacy and safety data from Study 10 and

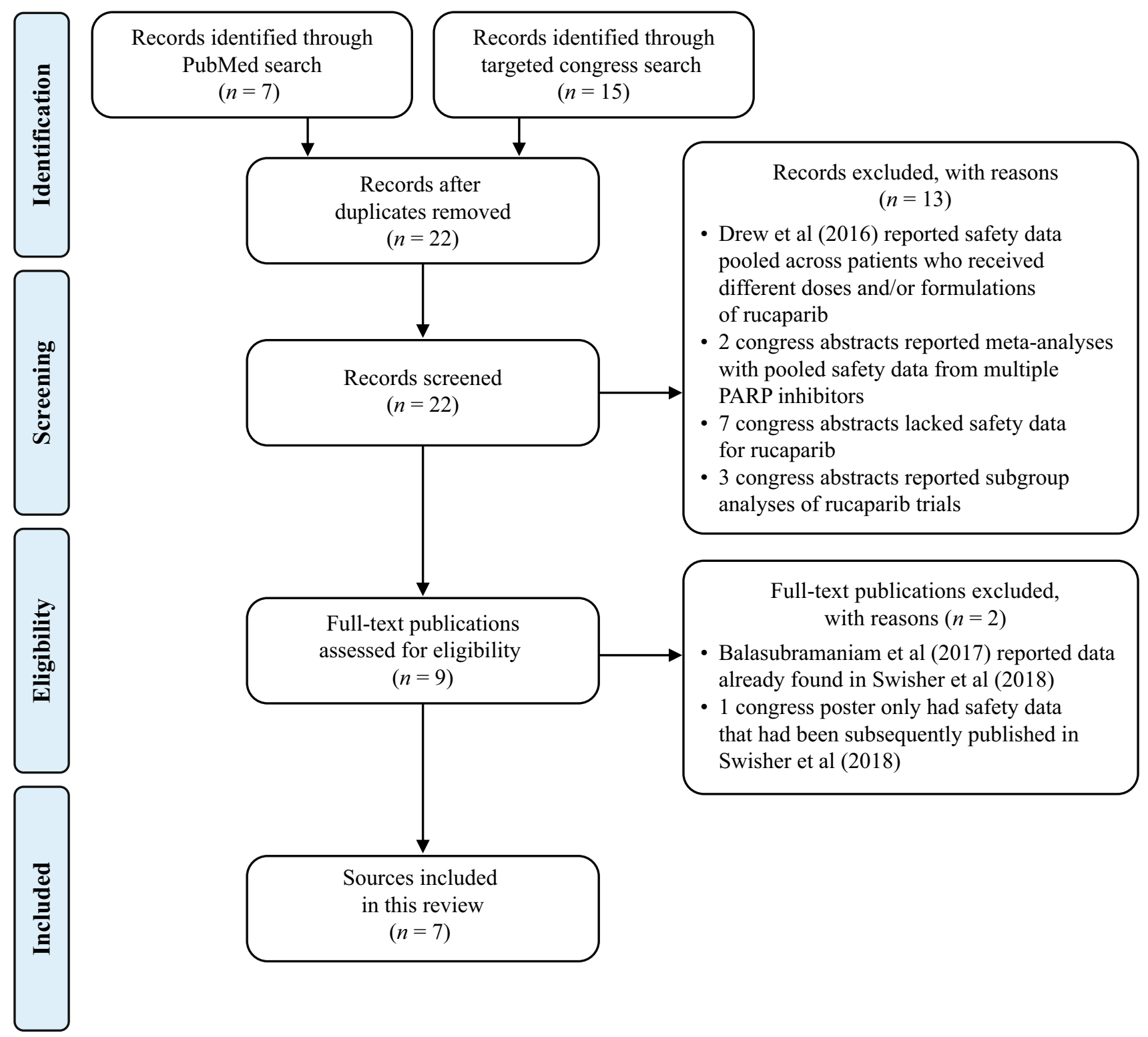

Fig. 1 Source literature selection. PARP poly(ADP-ribose) polymerase 
ARIEL2; data from Kristeleit et al. [10] were more recent, with a larger population, therefore these data are reported. Additional data from Oza et al. [9] are reported where relevant. Coleman et al. [11] reported efficacy and safety data from ARIEL3.

We also manually reviewed proceedings from the American Society of Clinical Oncology annual meetings and the European Society for Medical Oncology congresses from January 2016 to March 2020 to identify abstracts and presentations that reported safety data not captured in publications from the PubMed search (Fig. 1). In our congress search, we identified two presentations with additional safety data not available in the PubMed publications: Kristeleit et al. [20] and Kristeleit et al. [21].

We manually extracted the incidence and time to onset of TEAEs from the text and tables of eligible publications. We also extracted data regarding the rates and reasons for treatment interruptions, dose reductions, and discontinuations. Upon request, Clovis Oncology, Inc., provided additional safety data from a visit cut-off date of 31 December 2017 (i.e., the same as Kristeleit et al. [21]), including data from an updated safety analysis of ARIEL3 reported in a manuscript recently accepted for publication that was not yet indexed in PubMed (Ledermann et al. [19]).

For each of the most frequent TEAEs, we identified and summarized the guidance for management from available sources, including publicly available protocols of the clinical trials; information published in prescribing information (European Medicines Agency Summary of Product Characteristics [SmPC] and US Prescribing Information); and guidelines published by international and national oncology associations (e.g., European Society for Medical Oncology and National Comprehensive Cancer Network). The clinical experience of the authors has also been included in these recommendations.

\section{Rucaparib Safety Profile}

Integrated safety data from Study 10 and ARIEL2 (treatment setting) and ARIEL3 (maintenance setting) show that the most frequently occurring TEAEs of any grade with rucaparib in both settings include nausea, asthenia/fatigue (combination of preferred terms), vomiting, anemia/ decreased hemoglobin (combination of preferred terms), abdominal pain (including lower and upper), constipation, dysgeusia, and increased alanine aminotransferase (ALT)/aspartate aminotransferase (AST) (combination of preferred terms; Table 2). The most frequently occurring grade 3 or higher TEAEs in both settings included anemia/ decreased hemoglobin, increased ALT/AST, and asthenia/ fatigue. Median time to onset across settings was within
30 days for the majority of frequently reported any-grade TEAEs, although the TEAEs of anemia/decreased hemoglobin, thrombocytopenia/decreased platelet count (combination of preferred terms), and abdominal pain (including lower and upper) had median onset times $>30$ days [21]. Grade 3 or higher TEAEs had median onset times $>30$ days, apart from increased ALT/AST (median onset, 15 days; the earliest assessment was at 15 days) [21].

In the treatment and maintenance settings, $65.5 \%$ and $71.8 \%$ of patients who received rucaparib monotherapy required treatment interruption and/or dose reduction, respectively, due to a TEAE, the most frequent of which were anemia/decreased hemoglobin, asthenia/fatigue, and nausea (Tables 3, 4) [10] (data on file, Clovis Oncology, Inc. Boulder, CO, USA). In the treatment setting, median dose intensity (actual dose received/first dose received) was 0.92 [20], demonstrating that patients remained on or near the 600-mg twice daily dose for the duration of treatment. TEAEs leading to dose reduction and/or interruption typically occurred approximately 30 days after initiation of rucaparib. In the integrated analysis of safety data across trials, the median (95\% confidence interval [CI]) time to the start of the first TEAE leading to a dose reduction was 35.5 (29.0-43.0) days with rucaparib (data on file, Clovis Oncology, Inc.). The median $(95 \% \mathrm{CI})$ time to the start of the first TEAE leading to a treatment interruption was 32.0 (29.0-42.0) days with rucaparib (data on file, Clovis Oncology, Inc.).

The incidence of discontinuations due to a TEAE (excluding disease progression) was $16.8 \%$ and $15.3 \%$ in the treatment and maintenance settings, respectively (Tables 3, 4) [10, 19], with an incidence of $16.2 \%$ in the integrated safety analysis [21]. The most frequent TEAE leading to discontinuation in the treatment setting was asthenia/fatigue [10], whereas the most frequent TEAE leading to discontinuation in the maintenance setting was thrombocytopenia/decreased platelet count [19]. Discontinuations for other TEAEs were infrequent. Notably, only two patients $(0.2 \%)$ discontinued due to grade 3 or higher increased ALT/AST across clinical trials [21]. TEAEs leading to discontinuation generally started after the second month of treatment. The median (95\% CI) time to the start of TEAEs that led to dose discontinuation in the integrated safety analysis was 85.0 (55.0-110.0) days with rucaparib (data on file, Clovis Oncology, Inc.).

An analysis of all clinical studies of rucaparib identified 1321 patients who received at least one dose of oral rucaparib, regardless of tumor type. In this population, myelodysplastic syndrome or acute myeloid lymphoma was reported in $0.5 \%$ of patients during treatment and the 28 -day safety follow-up period, and $1.3 \%$ of patients who had long-term safety follow-up [13]. 
Table 2 Most frequently occurring $(\geq 20 \%)$ TEAEs of any grade with rucaparib in the treatment setting (integrated safety data from Study 10 Parts 1, 2A, 2B, and 3, and ARIEL2 Parts 1 and 2 [10]) and in the maintenance setting (ARIEL3 [19]), and an integrated analysis of safety across both settings (Kristeleit et al. [21] and data on file, Clovis Oncology, Inc., Boulder, CO, USA)

\begin{tabular}{|c|c|c|c|c|c|c|}
\hline & \multicolumn{2}{|c|}{ Treatment setting $[n=565]$} & \multicolumn{2}{|c|}{ Maintenance setting $[n=372]$} & \multicolumn{2}{|c|}{$\begin{array}{l}\text { Integrated safety analysis } \\
{[n=937]}\end{array}$} \\
\hline & Any grade & Grade 3 or higher & Any grade & Grade 3 or higher & Any grade & Grade 3 or higher \\
\hline Any TEAE & $565(100)$ & $357(63.2)$ & $372(100)$ & $222(59.7)$ & $937(100)$ & $579(61.8)$ \\
\hline Nausea & $439(77.7)$ & $29(5.1)$ & $282(75.8)$ & $14(3.8)$ & $721(76.9)$ & $43(4.6)$ \\
\hline Asthenia/fatigue $^{\mathrm{a}}$ & $422(74.7)$ & $64(11.3)$ & $263(70.7)$ & $26(7.0)$ & $685(73.1)$ & $90(9.6)$ \\
\hline Vomiting & $259(45.8)$ & $25(4.4)$ & $138(37.1)$ & $15(4.0)$ & $397(42.4)$ & $40(4.3)$ \\
\hline Anemia/decreased hemoglobin ${ }^{a}$ & $250(44.2)$ & $137(24.2)$ & $145(39.0)$ & $80(21.5)$ & $395(42.2)$ & $217(23.2)$ \\
\hline Abdominal pain ${ }^{\mathrm{b}}$ & $186(32.9)$ & $23(4.1)$ & $112(30.1)$ & $11(3.0)$ & $388(41.4)$ & $40(4.3)$ \\
\hline Constipation & $215(38.1)$ & $8(1.4)$ & $141(37.9)$ & $7(1.9)$ & $356(38.0)$ & $15(1.6)$ \\
\hline Dysgeusia & $204(36.1)$ & $1(0.2)$ & $148(39.8)$ & 0 & $352(37.6)$ & $1(0.1)$ \\
\hline Increased ALT/AST ${ }^{\mathrm{a}}$ & $223(39.5)$ & $61(10.8)$ & $129(34.7)$ & $38(10.2)$ & $352(37.6)$ & $99(10.6)$ \\
\hline Decreased appetite & $219(38.8)$ & $16(2.8)$ & $88(23.7)$ & $3(0.8)$ & $307(32.8)$ & $19(2.0)$ \\
\hline Diarrhea & $184(32.6)$ & $13(2.3)$ & $121(32.5)$ & $2(0.5)$ & $305(32.6)$ & $15(1.6)$ \\
\hline $\begin{array}{l}\text { Thrombocytopenia/decreased } \\
\text { platelet count }^{\mathrm{a}}\end{array}$ & $136(24.1)$ & $36(6.4)$ & $109(29.3)$ & $20(5.4)$ & $245(26.1)$ & $56(6.0)$ \\
\hline Increased blood creatinine & $125(22.1)$ & $3(0.5)$ & $61(16.4)$ & $1(0.3)$ & $186(19.9)^{\mathrm{c}}$ & $4(0.4)^{\mathrm{c}}$ \\
\hline Dyspnea & $127(22.5)$ & $5(0.9)$ & $53(14.2)$ & 0 & $180(19.2)^{\mathrm{c}}$ & $5(0.5)^{\mathrm{c}}$ \\
\hline
\end{tabular}

Data are expressed as $n(\%)$

TEAEs are sorted by decreasing incidence in the integrated safety analysis

$A L T$ alanine aminotransferase, $A S T$ aspartate aminotransferase, TEAE treatment-emergent adverse event

${ }^{\text {a }}$ To ensure full representation of similar TEAEs, certain terms were combined

${ }^{b}$ Data for the treatment and maintenance settings only include the preferred term 'abdominal pain'; data from the integrated safety analysis includes preferred terms of 'abdominal pain', 'abdominal pain lower', and 'abdominal pain upper'

${ }^{\mathrm{c}}$ Data on file

\section{General Advice for Dosing and Delivery of Rucaparib}

The starting dose of rucaparib is $600 \mathrm{mg}$ twice daily (two 300-mg tablets twice daily) [13]. Patients should take rucaparib every $12 \mathrm{~h}$. Rucaparib tablets can be taken with or without food. If a patient misses a dose (i.e., does not take it within $4 \mathrm{~h}$ of the scheduled time), they should skip the missed dose and resume taking the drug with their next scheduled dose. Missed or vomited doses should not be replaced.

As rucaparib is an oral medication taken in an outpatient setting, it is important to maintain regular clinical followup with patients, such as monthly follow-up during the first 3 months, with less frequent (e.g., every 3 months) follow-up thereafter for patients with good tolerability. Follow-up may be achieved through direct interactions with treating clinicians, interactions with other members of a multidisciplinary team (e.g., nurses and pharmacists), or through web-based applications [22-25]. Notably, recent surveys indicate that patients taking oral anticancer medications are interested in technologies to help them manage their treatment, such as pill reminders and apps that allow reporting of symptoms to physicians $[24,26]$. Electronic medication reminders have been shown to encourage adherence $[27,28]$, and the ability to report symptoms to clinicians or other healthcare team members via the internet has been associated with improvements in patient quality of life, better management of AEs, decreased hospitalizations, and longer overall survival [27, 29-32].

\section{Guidance for the Management of AEs During Rucaparib Treatment}

Many of the AEs that may occur during rucaparib treatment also occur with other PARP inhibitors and are generally not severe or life-threatening [7-11, 14, 15, 19, 21, 33-43]. Patients should be informed about the AEs that may occur 
Table 3 Most frequent TEAEs requiring a dose reduction/interruption or discontinuation of rucaparib in the treatment setting (integrated safety data from Study 10 Parts 1, 2A, 2B, and 3, and ARIEL2 Parts 1 and 2 [10])

\begin{tabular}{|c|c|}
\hline & $\begin{array}{l}\text { Rucaparib } \\
\text { treatment } \\
\text { setting }[n=565]\end{array}$ \\
\hline Patients who had a dose reduction due to a TEAE & $260(46.0)$ \\
\hline $\begin{array}{l}\text { Patients who had a dose interruption due to a } \\
\text { TEAE }\end{array}$ & $340(60.2)$ \\
\hline \multicolumn{2}{|l|}{$\begin{array}{l}\text { Most frequent TEAEs requiring a } \\
\text { dose reduction and/or interruption }\end{array}$} \\
\hline Anemia/decreased hemoglobin ${ }^{a}$ & $125(22.1)$ \\
\hline Asthenia/fatigue $^{\mathrm{a}}$ & $121(21.4)$ \\
\hline Nausea & $96(17.0)$ \\
\hline Thrombocytopenia/decreased platelet count ${ }^{\mathrm{a}}$ & $74(13.1)$ \\
\hline Vomiting & $72(12.7)$ \\
\hline Increased ALT/AST ${ }^{\mathrm{a}}$ & $45(8.0)$ \\
\hline Patients who discontinued due to a TEAE ${ }^{\mathrm{b}}$ & $95(16.8)$ \\
\hline \multicolumn{2}{|l|}{ Most frequent TEAEs leading to discontinuation } \\
\hline Asthenia/fatigue ${ }^{a}$ & $17(3.0)$ \\
\hline Small intestinal obstruction & $11(1.9)$ \\
\hline Thrombocytopenia/decreased platelet count ${ }^{\mathrm{a}}$ & $9(1.6)$ \\
\hline Anemia/decreased hemoglobin ${ }^{a}$ & $9(1.6)$ \\
\hline Nausea & $7(1.2)$ \\
\hline Vomiting & $7(1.2)$ \\
\hline
\end{tabular}

Data are expressed as $n(\%)$

$A L T$ alanine aminotransferase, $A S T$ aspartate aminotransferase, TEAE treatment-emergent adverse event

${ }^{a}$ To ensure full representation of similar TEAEs, certain terms were combined

${ }^{b}$ Excludes patients who discontinued because of disease progression

during rucaparib treatment and the timing they are most likely to occur, as well as their clinical consequences and the methods used to monitor and manage AEs. Clinicians should assure patients that most AEs are temporary and/or episodic.

Per rucaparib prescribing information, adverse reactions may be managed through dose interruptions and/or dose reductions according to the severity of the reaction $[12,13]$. It is recommended that the dose of rucaparib be reduced in 100-mg twice daily increments (Table 5). The rucaparib prescribing information also provides advice on the frequency of laboratory monitoring (e.g., monthly blood counts) and how to manage specific TEAEs (e.g., ALT/AST elevations, nausea/ vomiting); these are described in more detail in the sections below.

Oncology societies and working groups have developed guidelines for the management of several AEs observed during rucaparib treatment. Although not rucaparib-specific,
Table 4 Most frequent TEAEs requiring a dose reduction/interruption or discontinuation of rucaparib in the maintenance setting (ARIEL3 [19] and data on file, Clovis Oncology, Inc., Boulder, CO, USA)

\begin{tabular}{ll}
\hline & $\begin{array}{l}\text { Rucaparib } \\
\text { maintenance } \\
\text { setting }[n=372]\end{array}$ \\
\hline Patients who had a dose reduction due to a TEAE & $206(55.4)$ \\
Patients who had a dose interruption due to a TEAE & $243(65.3)$ \\
Most frequent TEAEs requiring a & \\
dose reduction and/or interruption $_{\text {Thrombocytopenia/decreased platelet count }}{ }^{\mathrm{a}}$ & $67(18.0)^{\mathrm{b}}$ \\
Anemia/decreased hemoglobin $^{\mathrm{a}}$ & $66(17.7)^{\mathrm{b}}$ \\
Nausea & $56(15.1)^{\mathrm{b}}$ \\
Patients who discontinued due to a TEAE & $57(15.3)$ \\
Most frequent TEAEs leading to discontinuation & \\
Thrombocytopenia/decreased platelet count & \\
Anemia/decreased hemoglobin & \\
Nausea & $11(3.0)$ \\
\hline
\end{tabular}

Data are expressed as $n(\%)$

TEAE treatment-emergent adverse event

${ }^{\text {a }}$ To ensure full representation of similar TEAEs, certain terms were combined

${ }^{\mathrm{b}}$ Data on file

${ }^{\mathrm{c}}$ Excludes patients who discontinued because of disease progression

these guidelines can be employed by clinicians and adapted as needed to provide patients with optimal care.

\subsection{Nonhematologic TEAEs}

\subsubsection{Nausea and Vomiting}

Nausea and vomiting may occur when starting rucaparib (median time to onset [95\% CI], 5 [4-5] and 15 [13-23] days, respectively), although the majority of cases are grade 1 or 2 [21]. These AEs may be managed through lifestyle changes, such as taking rucaparib later in the day (e.g. 11:00 am and 11:00 pm vs. 9:00 am and 9:00 pm) [44], eating small, frequent meals, and using natural antiemetics such as ginger (Fig. 2). In our experience, antiemetics such as metoclopramide, prochlorperazine, or cyclizine may be useful for some patients, with adjustments to the antiemetic medication as needed in the case of breakthrough nausea and/or vomiting. 5-hydroxytryptamine type 3 (5- $\mathrm{HT}_{3}$ [serotonin]) receptor antagonists, corticosteroids (e.g. dexamethasone twice daily for 3-4 days), and neurokinin-1 antagonists are 
Table 5 Recommended dose adjustments with rucaparib [13]

\begin{tabular}{ll}
\hline Dose reduction & Dose \\
\hline Starting dose & $600 \mathrm{mg}$ twice daily (two 300-mg tablets twice daily) \\
First dose reduction & $500 \mathrm{mg}$ twice daily (two 250-mg tablets twice daily) \\
Second dose reduction & $400 \mathrm{mg}$ twice daily (two 200-mg tablets twice daily) \\
Third dose reduction & $300 \mathrm{mg}$ twice daily (one 300-mg tablet twice daily) \\
\hline
\end{tabular}

\begin{tabular}{|c|c|}
\hline & Nausea/vomiting \\
\hline & $\begin{array}{l}\text { Rucaparib has moderate emetogenic potential (i.e. } 30 \%-90 \% \text { incidence); } \\
\text { prevention throughout the full period of risk should be the primary goal }\end{array}$ \\
\hline $\begin{array}{l}\text { Acute nausea } \\
\text { and vomiting }\end{array}$ & $\begin{array}{l}\text { - Educate patients on lifestyle changes including eating small, frequent meals and by } \\
\text { taking the first dose of rucaparib later in the day, e.g. } 11 \text { AM vs } 9 \text { AM } \\
\text { - Consider providing prophylactic antiemetic regimen, e.g. metoclopramide, } \\
\text { prochlorperazine, or cyclizine }^{\mathrm{a}}\end{array}$ \\
\hline $\begin{array}{r}\text { Breakthrough } \\
\text { nausea and } \\
\text { vomiting }\end{array}$ & $\begin{array}{l}\text { - Consider adding an antiemetic with a different mechanism of action from those used } \\
\text { for prophylaxis }\end{array}$ \\
\hline & $\begin{array}{l}\text { - If not adequately controlled by symptomatic management, consider dose } \\
\text { interruption and/or reduction }\end{array}$ \\
\hline
\end{tabular}

Fig. 2 Guidance for managing nausea/vomiting [13, 45]. ${ }^{\text {a }}$-hydroxytryptamine type 3 (5-HT 3 [serotonin]) receptor antagonists, corticosteroids (e.g. dexamethasone twice daily for 3-4 days), and neurokinin-1 antagonists are rarely required but could be considered

\section{Constipation}

\section{Constipation is common in patients with advanced cancer; rucaparib may increase the likelihood of developing constipation}

Assessment and $\begin{aligned} & \text { - Evaluate all cancer patients for constipation } \\ & \text { diagnosis } \begin{array}{l}\text { Use full medical history to determine possible causes of constipation } \\ \text { Perform physical examination }\end{array}\end{aligned}$

Fig. 3 Guidance for managing constipation $[13,46]$. ${ }^{\mathrm{a}}$ Enemas are contraindicated for patients with neutropenia or thrombocytopenia, paralytic ileus or intestinal obstruction, recent colorectal or gyneco- logic surgery, recent anal or rectal trauma, severe colitis, inflammation or infection of the abdomen, toxic megacolon, undiagnosed abdominal pain, or recent radiotherapy to the pelvic area 
Diarrhea $^{a}$

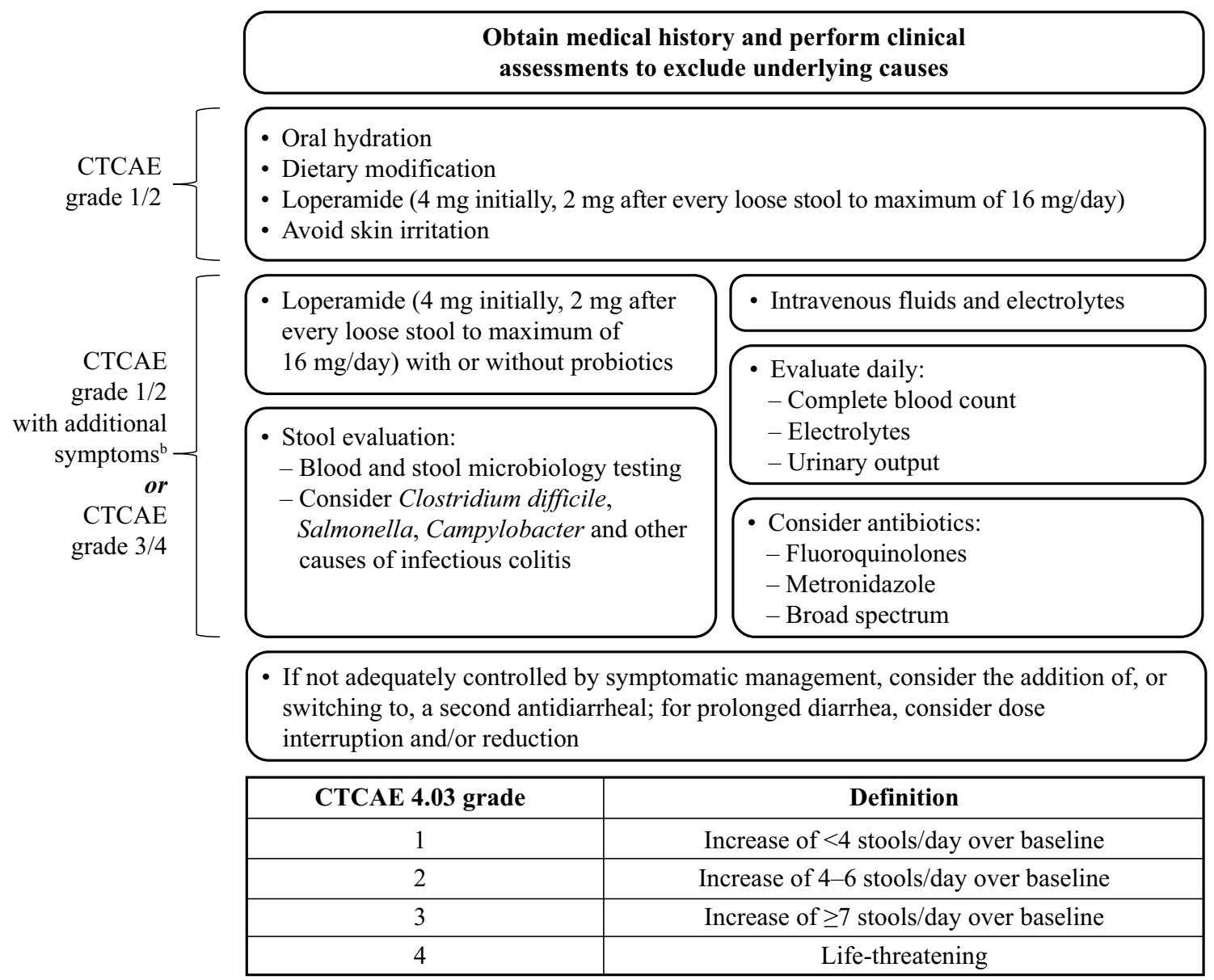

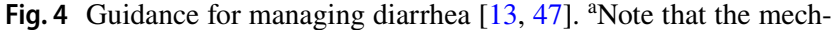
anism of action underlying diarrhea that may occur with PARP inhibitor treatment has not been elucidated; there is a lack of consensus for management/treatment of diarrhea from new targeted therapies.

rarely required but could be considered [45]. Dose reduction or interruption should be considered if symptoms are not adequately controlled [13].

\subsubsection{Constipation}

Similar to other gastrointestinal AEs that may occur with rucaparib, constipation tends to be observed in the beginning (median time to onset [95\% CI], 29 [22-43] days), although it is usually grade 2 or lower [21]. Constipation is also common in patients with ovarian cancer; therefore, all patients should be evaluated for constipation, and other causes should be excluded when present (Fig. 3) [46]. As part of discussions about treatment, clinicians should educate patients on self-care and prevention strategies. When needed, laxatives (osmotic or stimulant) may be used. For full rectum or fecal impaction, suppositories and/or enemas may be provided.
Guidelines presented are based on experience with other anticancer treatments. ${ }^{b}$ For example, nausea, emesis, cramps, fever, and blood in the feces. CTCAE Common Terminology Criteria for Adverse Events, PARP poly(ADP-ribose) polymerase

\subsubsection{Diarrhea}

Although generally low grade, diarrhea often occurs when patients initiate rucaparib (median time to onset $[95 \% \mathrm{CI}]$, 29 [17-35] days) [21]. Clinicians should exclude other causes (e.g. bowel obstruction, concomitant medication) and treat as needed (Fig. 4) [47]. Interventions for mild-to-moderate diarrhea may include oral hydration, dietary adjustments, and/or antidiarrheal medication (e.g. loperamide). For patients with more severe diarrhea, consider providing antidiarrheal medication (with or without probiotics), intravenous fluids, and electrolyte replacement. Antibiotics may need to be provided if infection is confirmed. The addition of, or switching to, a second alternative oral antidiarrheal medication should be considered if diarrhea remains uncontrolled; dose interruption and/or reduction may be needed for prolonged diarrhea. 


\section{Fatigue}

\begin{tabular}{|c|c|c|c|}
\hline \multirow[b]{2}{*}{$\left.\begin{array}{r}\text { CTCAE } \\
\operatorname{grade} 1 / 2\end{array}\right\}$} & \multicolumn{3}{|c|}{$\begin{array}{l}\text { Expect symptoms of fatigue, screen for fatigue at regular intervals; } \\
\text { advise patients that fatigue does not necessarily indicate disease progression }\end{array}$} \\
\hline & $\begin{array}{l}\text { Instruct patients on } \\
\text { general strategies for } \\
\text { management of fatigue: } \\
\text { - Self-monitoring } \\
\text { - Conserve energy } \\
\text { - Use distraction } \\
\text { - Mindfulness } \\
\text { - Specialist advice }\end{array}$ & $\begin{array}{l}\text { Consider nonpharmacologic } \\
\text { intervention: } \\
\text { - Low intensity activities } \\
\text { - Massage or acupuncture } \\
\text { - Group or individual } \\
\text { psychotherapy } \\
\text { - Dietary consultation } \\
\text { - Mood/sleep disorder therapy } \\
\text { (e.g. CBT/bright light) }\end{array}$ & $\begin{array}{l}\text { Consider pharmacologic } \\
\text { intervention: } \\
\text { - Antidepressants } \\
\text { - Psychostimulants } \\
\text { - Treatment adjustment } \\
\text { for comorbidities and } \\
\text { sleep/nutritional disorders }\end{array}$ \\
\hline \multirow[t]{6}{*}{$\begin{array}{l}\text { CTCAE } \\
\text { grade } 3 / 4\end{array}$} & $\begin{array}{l}\text { Obtain focused medical } \\
\text { - Disease status } \\
\text { - Concomitant medica } \\
\text { - Fatigue history }\end{array}$ & $\begin{array}{l}\text { - Manage/ } \\
\text { other fac } \\
\text { - Anemi } \\
\text { - Physic } \\
\text { - Psych } \\
\text { - Nutrit }\end{array}$ & $\begin{array}{l}\text { current symptoms and } \\
\text { istress } \\
\text { ficits }\end{array}$ \\
\hline & CTCAE $4.03 \mathrm{grad}$ & & \\
\hline & 1 & Fatigu & d by rest \\
\hline & 2 & $\begin{array}{r}\text { Fatigue } n \\
\text { limiting instrume }\end{array}$ & $\begin{array}{l}\text { ved by rest; } \\
\text { vities of daily living }\end{array}$ \\
\hline & 3 & $\begin{array}{r}\text { Fatigue } n \\
\text { limiting self-car }\end{array}$ & $\begin{array}{l}\text { ved by rest; } \\
\text { ties of daily living }\end{array}$ \\
\hline & 4 & & \\
\hline
\end{tabular}

Fig. 5 Guidance for managing fatigue $[48,49]$. CBT cognitive behavioral therapy, CTCAE Common Terminology Criteria for Adverse Events

\subsubsection{Other Gastrointestinal AEs}

Patients taking rucaparib may also experience abdominal pain (including lower and upper; median time to onset [95\% CI], 45 [33-56] days) [21]. We suggest interrupting rucaparib for 3 days and providing the patient with scopolamine three times daily. Rucaparib can then be resumed at the same dose, or at a reduced dose depending on the severity of the symptoms. We encourage patients who experience decreased appetite (median time to onset [95\% CI], 22 [16-29] days) [21] to eat their favorite foods, to have small and frequent meals, and to preferentially eat salty and dry food.

\subsubsection{Asthenia/Fatigue}

Symptoms of fatigue should be expected (median time to onset [95\% CI], 15 [13-15] days) [21], and patients should be advised that these do not necessarily indicate disease progression (Fig. 5) [48, 49]. For patients with mild asthenia/fatigue (e.g. grade 1 or 2), clinicians can educate on general lifestyle adjustments (e.g. energy conservation). Nonpharmacologic (e.g. physical activity and nutritional consultation) and pharmacologic (e.g. psychostimulants) interventions can also aid in the management of fatigue. For patients with moderate-to-severe fatigue (e.g. grade 3 or 4 ), more extensive examination may be warranted to determine whether other factors are contributing (e.g. concomitant medications, pain, or anemia). Rucaparib dose reduction or interruption should be considered if symptoms are not adequately controlled [13].

\subsubsection{Dysgeusia}

Dysgeusia, mainly grade 1 or 2 , may be experienced by patients receiving rucaparib (median time to onset [95\% CI], 7 [5-9] days) [21]. Clinicians should advise patients that changes in diet (e.g. increasing/decreasing seasonings, rotating food choices) and oral hygiene regimens (e.g. more frequent tooth brushing, use of mouthwashes) may help ameliorate symptoms [50]. 


\section{Increased ALT/AST}

\begin{tabular}{|c|c|c|}
\hline \multirow[b]{2}{*}{$\begin{array}{r}\text { CTCAE } \\
\text { grade } 1 / 2\end{array}$} & \multicolumn{2}{|c|}{$\begin{array}{l}\text { Increases in ALT/AST occur early in treatment, are generally transient } \\
\text { and are rarely associated with bilirubin increases } \\
\text { Liver function tests should be carried out regularly (e.g. at least bimonthly } \\
\text { for the first } 3 \text { months and monthly thereafter) }\end{array}$} \\
\hline & \multicolumn{2}{|l|}{$\begin{array}{l}\text { - Eliminate other causes } \\
\text { - Maintain rucaparib dose }\end{array}$} \\
\hline $\begin{array}{r}\text { CTCAE } \\
\text { grade } 3\end{array}$ & \multicolumn{2}{|c|}{$\begin{array}{l}\text { - If no other signs of liver dysfunction: } \\
\text { - Rucaparib dose can be maintained if bilirubin }<\text { ULN and alkaline } \\
\text { phosphatase }<3 \times \text { ULN } \\
\text { - ALT/AST levels should be monitored weekly until resolution to grade } \leq 2 \\
\text { - Treatment should be interrupted if levels do not decline to grade } \leq 2 \text { within } 2 \text { weeks } \\
\text { - Once resolved to grade } \leq 2 \text {, resume rucaparib at the same dose or at a reduced dose } \\
\text { - If signs of liver dysfunction and/or abnormalities in bilirubin or alkaline phosphatase } \\
\text { - Interrupt treatment and monitor ALT/AST levels weekly until values return to } \\
\text { grade } \leq 2 \\
\text { - Once resolved to grade } \leq 2 \text {, resume rucaparib at the same dose or at a reduced dose }\end{array}$} \\
\hline \multirow[t]{6}{*}{$\begin{array}{r}\text { CTCAE } \\
\text { grade } 4\end{array}$} & \multicolumn{2}{|c|}{$\begin{array}{l}\text { - Interrupt treatment until values return to grade } \leq 2 \\
\text { - Once resolved, resume rucaparib with a dose reduction and monitor ALT/AST levels } \\
\text { weekly for } 3 \text { weeks }\end{array}$} \\
\hline & CTCAE 4.03 grade & Definition \\
\hline & 1 & ALT or AST $>$ ULN $-3 \times$ ULN \\
\hline & 2 & ALT or AST $3-5 \times$ ULN \\
\hline & 3 & ALT or AST $5-20 \times$ ULN \\
\hline & 4 & ALT or AST $>20 \times \mathrm{ULN}$ \\
\hline
\end{tabular}

Fig. 6 Guidance for managing increased ALT/AST [13]. ${ }^{a}$ Author recommendation based on clinical experience. ALT alanine aminotransferase, $A S T$ aspartate aminotransferase, CTCAE Common Terminology Criteria for Adverse Events, ULN upper limit of normal

\subsubsection{Increased ALT/AST}

Liver transaminase elevations are specific to rucaparib and are frequently observed during treatment. We recommend regular liver function tests (e.g. at least bimonthly for the first 3 months). Increases in ALT and/or AST typically occur within the first few cycles (median time to onset [95\% CI], 15 [14-15] days) [21]. According to the European Medicines Agency's SmPC, these elevations are generally transient and reversible and typically return to normal values without intervention or impact on liver function [9, 11, 13]. Grade 1-3 increases in ALT/AST can generally be managed without treatment modification (Fig. 6) [13]. For grade 3 increases in ALT/AST, per guidance in the SmPC, rucaparib can be continued at the same dose if bilirubin levels are less than the upper limit of normal and alkaline phosphatase levels are less than three times the upper limit of normal [13]. Levels of ALT and AST should be monitored weekly until resolution to grade 2 or lower. Treatment should be interrupted if levels do not decline to grade 2 or lower within 2 weeks, then rucaparib should be resumed at the same or reduced dosage. We recommend that treatment should be interrupted if grade 3 ALT/AST increase is accompanied by bilirubin and/or alkaline phosphatase abnormalities or other symptoms of liver toxicity. The patient's ALT and AST levels should be monitored weekly, and rucaparib should be resumed at the same or reduced dosage once resolved (i.e. grade 2 or lower). For grade 4 ALT/AST increase, treatment should be interrupted until values return to grade 2 or lower; rucaparib may then be resumed at a reduced dosage, with weekly monitoring of liver function tests for 3 weeks [13]. 
Hematologic AEs

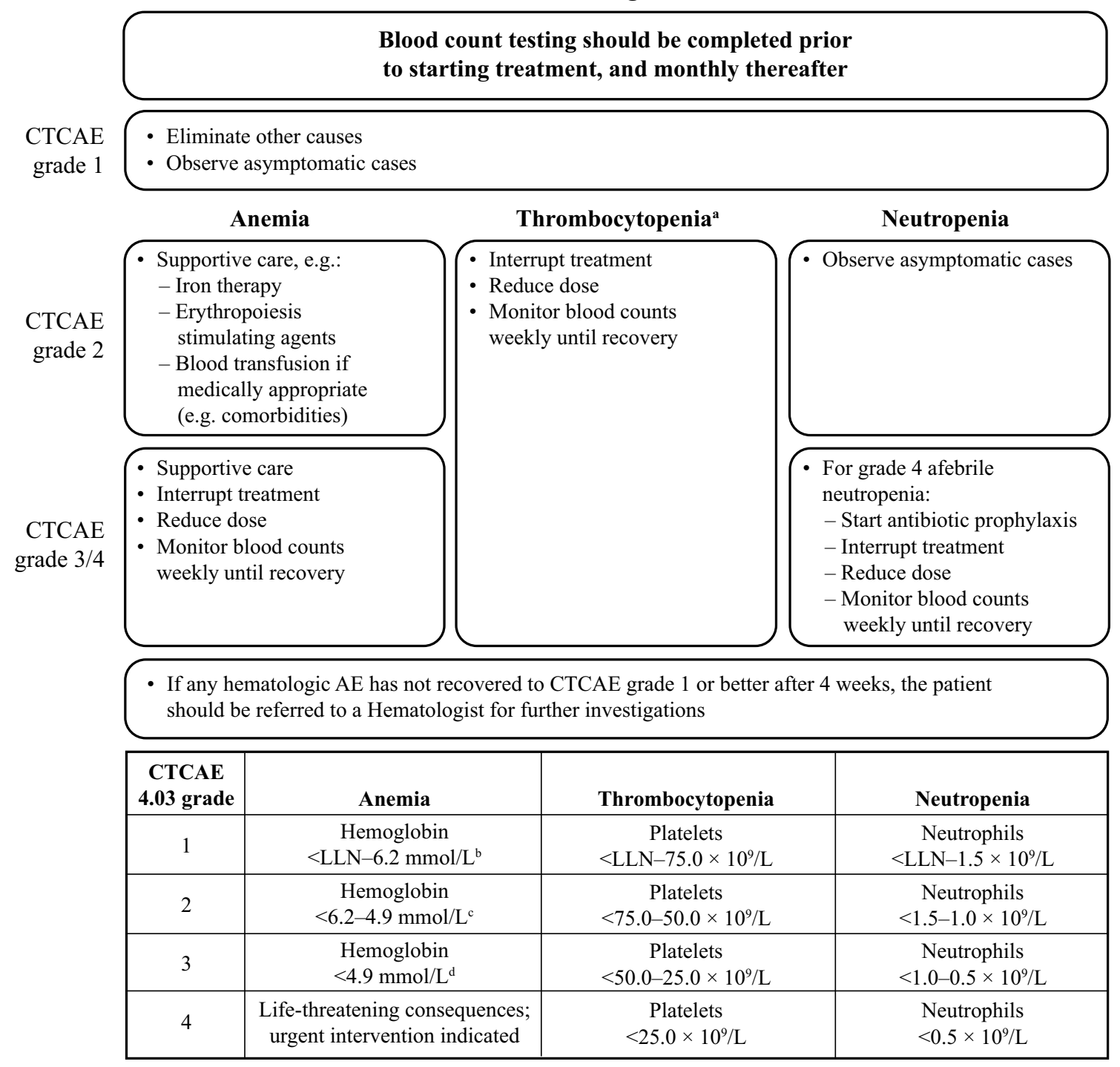

Fig. 7 Guidance for managing hematologic toxicities [13, 54-56].

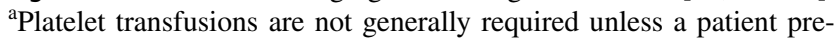
sents with bleeding; ${ }^{\mathrm{b}}<\mathrm{LLN}-100 \mathrm{~g} / \mathrm{L} ;{ }^{\mathrm{c}}<100-80 \mathrm{~g} / \mathrm{L} ;{ }^{\mathrm{d}}<80 \mathrm{~g} / \mathrm{L}$.

\subsubsection{Increased Blood Creatinine}

Elevations in creatinine may be observed within the first weeks of rucaparib treatment, although levels tend to stabilize and remain within the normal range over time [9, 11]. Electrolytes should be checked at the start of treatment and monthly thereafter. No dose adjustment is needed for patients with mild-to-moderate renal impairment (creatinine clearance of $30-89 \mathrm{~mL} / \mathrm{min}$ ). Creatinine elevations have been linked to inhibition of the renal transporters MATE1 and MATE2-K by several PARP inhibitors [13, 51, 52], and may not be directly associated with renal toxicity. Mild serum creatinine elevations do not require dose modification.
$A E$ adverse event, CTCAE Common Terminology Criteria for Adverse Events, $L L N$ lower limit of normal

If creatinine levels rise substantially (e.g. grade 3 or higher), rucaparib treatment should be interrupted and other causes of renal dysfunction (e.g. obstruction, dehydration, concomitant medication) should be excluded through appropriate assessments. Alternative methods for assessing renal function may be needed as discordance between estimated glomerular filtration rate (GFR) based on serum creatinine levels and calculated GFR obtained through a nuclear medicine scan was commonly observed (63\% of matched assessments) in a retrospective study of patients who received PARP inhibitors [53]. If true renal dysfunction is confirmed, dose reduction may be required once creatinine levels have 
improved. If toxicity does not resolve to grade 1 or better within 14 days, rucaparib may need to be discontinued.

\subsubsection{Dyspnea}

Patients who present with dyspnea should be examined to exclude cardiac or lung disease (i.e. interstitial pneumonitis). We suggest that patients reduce, but not avoid, strenuous physical activity and have periods of rest throughout the day. For some patients, anxiolytics may help.

\subsection{Hematologic TEAEs}

\subsubsection{Anemia, Thrombocytopenia, or Neutropenia}

Blood counts should be monitored prior to treatment and monthly throughout treatment (Fig. 7) [13]. Events of myelosuppression may be observed after 8-10 weeks of rucaparib treatment [21]. For example, in an integrated analysis of safety data from patients in the treatment and maintenance settings, median (95\% CI) time to onset of anygrade anemia/decreased hemoglobin was 56 (53-57) days, and median $(95 \% \mathrm{CI})$ time to onset of grade 3 or higher anemia/decreased hemoglobin was 83 (74-85) days [21]. In the same analysis, median (95\% CI) time to onset of anygrade thrombocytopenia/decreased platelet count was 52 (43-57) days, and median (95\% CI) time to onset of grade 3 or higher thrombocytopenia/decreased platelet count was 47 (29-63) days [21]. Any-grade neutropenia/decreased neutrophil count was reported in $16.2 \%$ of patients in the integrated analysis of safety (median [95\% CI] time to onset, 67 [55-85] days), with $7.9 \%$ of patients having grade 3 or higher events (median [95\% CI] time to onset, 82 [57-85] days) [data on file, Clovis Oncology, Inc.].

In our experience, short-term interruptions in combination with iron and folate supplements are helpful for patients with grade 2 anemia/decreased hemoglobin. For patients with comorbidities or grade 3 or higher anemia/decreased hemoglobin, supportive care (e.g. transfusions [54-56]) and dose interruption should be considered [13]. Upon recovery to grade 1 or better, rucaparib can be restarted at a lower dose. For grade 2 or higher thrombocytopenia/decreased platelet count, we recommend rucaparib be interrupted and resumed at a lower dose upon recovery to grade 1 or better. Platelet transfusions are not generally required unless a patient presents with bleeding. Use of heparin may also cause thrombocytopenia, therefore concomitant medications should be reviewed. In our experience, patients with asymptomatic neutropenia/neutrophil count decrease can generally continue rucaparib without dose modification. In the case of grade 4 afebrile neutropenia, antibiotic prophylaxis should be started. Rucaparib should be held until recovery and resumed at a lower dose.

\subsubsection{Myelodysplastic Syndrome/Acute Myeloid Lymphoma}

If a patient has prolonged hematologic toxicity (e.g. grade 2 or higher for $>4$ weeks) following dose interruption/ reduction, or if myelodysplastic syndrome/acute myeloid lymphoma is suspected, clinicians should refer patients to a hematologist for further investigations [12, 13]. If myelodysplastic syndrome/acute myeloid lymphoma is confirmed, rucaparib should be discontinued $[12,13]$.

\section{Discussion}

Before initiating treatment with rucaparib, clinicians should discuss the intended goals of therapy as well as the AE profile of rucaparib with their patients. Clinicians should use these discussions to obtain an understanding of a patient's prior experience with toxicities from other treatments, provide information about what to expect while receiving rucaparib, and outline the methods available for managing expected AEs. Such discussions are particularly important for PARP inhibitor maintenance treatment that is initiated immediately after prior chemotherapy. For patients with ovarian cancer, this approach likely differs from their previous experience with cycle-limited chemotherapy (alone or in combination with bevacizumab) followed by a treatment-free period. Furthermore, in the maintenance setting, treatment may be administered for an extended duration and efforts should be made to ensure patients do not discontinue treatment due to manageable AEs and therefore derive optimal clinical benefit. This may be achieved through engagement of multidisciplinary teams (e.g. clinicians, nurses, and pharmacists) and use of web-based interventions to encourage adherence and enable the prompt identification of AEs.

In a survey of more than 1800 European women with ovarian cancer (Expression III [NOGGO/ENGOT-ov4GCIG]), $>80 \%$ of responders desired more information about the possible AEs of therapy, with approximately $40 \%$ of patients requesting more information on the anticipated timing of life-impacting changes [57]. Another international NOGGO survey of more than 2100 European women with ovarian cancer who were under consideration for maintenance therapy (Expression IV [NOGGO/GCIG/ENGOTov22]) reported that the AEs of most concern (in $\geq 25 \%$ of respondents) were primarily nonhematologic and included polyneuropathy, nausea, alopecia, vomiting, and fatigue [16].

Patients eligible to receive maintenance therapy such as rucaparib may have experienced AEs with prior treatment and may share similar concerns as those in these studies. This highlights the need to educate patients on key differences between the frequency and/or severity of AEs that may 
occur during rucaparib treatment versus those associated with chemotherapy. For instance, any-grade gastrointestinal events, such as diarrhea and constipation, may occur more frequently with rucaparib than platinum-based chemotherapy $[10,19,21,58]$, although the majority of these are grade 1 or 2 and are readily managed. In contrast, grade 3 or 4 hematologic events, such as neutropenia and thrombocytopenia, are less common with rucaparib than with platinumbased chemotherapy $[10,19,21,58]$; the high frequency of hematologic events is among the reasons that chemotherapies are unsuitable for long-term treatment (e.g. maintenance therapy). ARIEL4 (CO-338-043; NCT02855944), an ongoing, randomized, phase III study evaluating rucaparib versus standard-of-care chemotherapy as treatment for patients with germline or somatic $B R C A$-mutated, relapsed, high-grade ovarian cancer who have received two or more prior chemotherapy regimens, may provide additional insight into the different $\mathrm{AE}$ profiles of rucaparib and chemotherapy.

AEs can have negative effects on a patient's daily activities and overall quality of life. Consequently, prompt recognition and management of these AEs is imperative to mitigate their impact on patients. In the treatment setting, ongoing disease symptoms may also influence patient experience and should be considered and evaluated throughout rucaparib treatment. In the maintenance setting, ongoing and prior AEs from the previous treatment (e.g. anemia from platinum-based chemotherapy) may have an impact on the types of AEs a patient experiences while receiving rucaparib. Furthermore, patients receiving rucaparib in the maintenance setting may have satisfactory control of disease-related symptoms because they have responded to platinum but may encounter new AEs during rucaparib treatment. Overall, the safety profile of rucaparib is similar between the treatment and maintenance settings; however, there are some differences, such as a higher incidence of any-grade vomiting and grade 3 or higher asthenia/fatigue in the treatment setting than in the maintenance setting. These differences could possibly be attributed to the overall health status of patients when initiating rucaparib. For example, in the treatment setting, patients may be experiencing fatigue associated with relapsed disease and thus may report asthenia/fatigue more frequently. Regardless of setting, patients should understand the balance between the benefits and risks of rucaparib therapy. For instance, rucaparib maintenance treatment may delay the need for subsequent chemotherapy, but it also has the potential to cause adverse effects.

Clinicians should also be aware of the typical timing for the onset of AEs that may occur during rucaparib treatment [21] and how these AEs may change over time (e.g. becoming less frequent or severe) so that they can adequately convey this information to patients and monitor accordingly. Some AEs, such as anemia/decreased hemoglobin and increased ALT/AST, are known to occur early during rucaparib treatment [21]. Anemia can be associated with symptoms that affect patient quality of life (e.g. light-headedness and fatigue) [56]; therefore, appropriate monitoring and intervention may help to reduce the impact of these AEs on patients' lives. Increases in ALT or AST are typically asymptomatic and normalize without intervention, although levels should be assessed regularly. Other AEs, such as constipation and diarrhea, may have an episodic profile; therefore, educating patients on their signs and symptoms may prompt them to communicate any concerns in a timely manner.

Clinicians should clearly communicate with patients about the dosing regimen for rucaparib, as the patient will be responsible for adhering to the twice-daily schedule. Patients should understand that, in contrast to chemotherapy, rucaparib in the maintenance setting is intended to be taken continuously over an extended period of time. Factors such as a patient's age, knowledge of the disease and therapy, and experience with AEs can influence adherence and persistence to oral anticancer therapies $[16,59,60]$, and should be taken into consideration during discussions with patients.

Adequate management of AEs that may occur during rucaparib treatment may include treatment interruptions and/ or dose reductions; clinicians should ensure that patients understand and can comply with such changes in treatment. Following a treatment interruption in response to a grade 3 or higher $\mathrm{AE}$, it is possible that a given $\mathrm{AE}$ may reoccur when returning to the prior dose level. In such cases, treatment should be held until resolution of the AE to grade 2 or lower before resuming treatment at a lower dose. There are no reported data regarding the effect on AEs that increasing the rucaparib dose may have in patients who have had dose reductions.

Many of the AEs that may occur during rucaparib treatment are observed with other agents in the PARP inhibitor class [7-11, 14, 15, 19, 21, 33-43]. The main TEAEs in patients with ovarian cancer who received olaparib include fatigue, nausea, vomiting, and anemia [14, 35, 36]. In patients who received olaparib maintenance treatment for more than 1 year in the SOLO2 trial, the incidence of TEAEs was lower in the second and subsequent years than in the first year [61]. The most frequent TEAEs in the second year were anemia, nausea, and vomiting, whereas the most frequent TEAEs in subsequent years were diarrhea, abdominal pain, and upper abdominal pain [61]. Most TEAEs associated with long-term olaparib maintenance treatment were low grade [61]. The most frequent TEAEs in patients with ovarian cancer who received niraparib include nausea, thrombocytopenia, fatigue/asthenia, and anemia [33, 34]. Notably, thrombocytopenia and hypertension are seen more often with niraparib [33, 34] than other PARP inhibitors [12, $13,35,36]$. Therefore, the safety profile and management of 
AEs is a relevant factor when selecting a targeted therapy for ovarian cancer.

Future trials should include analyses to identify predictive markers and factors for specific AEs of PARP inhibitors, which may include patient characteristics as well as AEs experienced with previous chemotherapies and targeted therapies. For example, a retrospective analysis of data from the NOVA trial identified baseline platelet count and baseline body weight as risk factors for increased incidence of grade 3 or higher thrombocytopenia [62]; however, further validation by prospective trials is needed.

\section{Summary}

When treating patients with rucaparib, clinicians should always consider the impact of AEs on adherence and patient quality of life. Effective communication between the healthcare team and patients and their caregivers before and throughout rucaparib treatment is crucial to ensure they understand the types of AEs to expect, when they are likely to occur, and the appropriate action to take, and clinicians should encourage the prompt reporting of symptoms. The majority of AEs observed with rucaparib can be easily managed, which may allow patients to continue receiving rucaparib treatment for optimal clinical benefit.

Acknowledgements Writing and editorial assistance funded by Clovis Oncology, Inc., were provided by Nathan Yardley, $\mathrm{PhD}$, and Shannon Davis of Ashfield Healthcare Communications (Middletown, CT, USA).

Author contribution DL had the idea for the article, and all authors were involved in identifying the relevant literature, evaluating the data, and drafting and/or critically revising the work.

Funding This work was funded by Clovis Oncology, Inc.

\section{Compliance with Ethical Standards}

Conflict of interest Domenica Lorusso has served in a consulting or advisory role for Clovis Oncology, AstraZeneca, F. Hoffman-La Roche, ImmunoGen, Merck, PharmaMar, Takeda, and Tesaro, and has received support for travel or accommodation from F. HoffmanLa Roche and PharmaMar. Jesús García-Donas has received research funding from AstraZeneca, and has served on advisory boards for Clovis Oncology, Genentech/Roche, and Janssen. Jalid Sehouli has served in a consulting or advisory role for Clovis Oncology, AstraZeneca, Bristol-Myers Squibb, Eisai, Eli Lilly, F. Hoffman-La Roche, Merck, Pfizer Inc., Sanofi, and Tesaro, and has received support for travel or accommodation from Clovis Oncology, AstraZeneca, F. Hoffman-La Roche, PharmaMar, and Tesaro. Florence Joly has served in a consulting or advisory role for Clovis Oncology, Astellas, AstraZeneca, Bayer AG, Bristol-Myers Squibb, F. Hoffman-La Roche, Ipsen, Janssen, Merck, Novartis, Pfizer, Sanofi, and Tesaro, and has received support for travel or accommodation from Astellas, AstraZeneca, Bristol-Myers Squibb, F. Hoffman-La Roche, Ipsen, Janssen, and Tesaro.
Open Access This article is licensed under a Creative Commons Attribution-NonCommercial 4.0 International License, which permits any non-commercial use, sharing, adaptation, distribution and reproduction in any medium or format, as long as you give appropriate credit to the original author(s) and the source, provide a link to the Creative Commons licence, and indicate if changes were made. The images or other third party material in this article are included in the article's Creative Commons licence, unless indicated otherwise in a credit line to the material. If material is not included in the article's Creative Commons licence and your intended use is not permitted by statutory regulation or exceeds the permitted use, you will need to obtain permission directly from the copyright holder.To view a copy of this licence, visit http://creativecommons.org/licenses/by-nc/4.0/.

\section{References}

1. National Comprehensive Cancer Network (NCCN) Clinical Practice Guidelines in Oncology. Ovarian cancer including fallopian tube cancer and primary peritoneal cancer (Version 3.2019). https ://www.nccn.org/professionals/physician_gls/pdf/ovarian.pdf. Accessed 3 Mar 2020.

2. Ledermann JA, Raja FA, Fotopoulou C, Gonzalez-Martin A, Colombo N, Sessa C, et al. Newly diagnosed and relapsed epithelial ovarian carcinoma: ESMO Clinical Practice Guidelines for diagnosis, treatment and follow-up. Ann Oncol. 2013;24:vi24 vi32. https://doi.org/10.1093/annonc/mdt333.

3. Kemp Z, Ledermann JA. Update on first-line treatment of advanced ovarian carcinoma. Int J Womens Health. 2013;5:45-51. https://doi.org/10.2147/IJWH.S30231.

4. Wahlberg E, Karlberg T, Kouznetsova E, Markova N, Macchiarulo A, Thorsell AG, et al. Family-wide chemical profiling and structural analysis of PARP and tankyrase inhibitors. Nat Biotechnol. 2012;30:283-8. https://doi.org/10.1038/nbt.2121.

5. Farmer H, McCabe N, Lord CJ, Tutt ANJ, Johnson DA, Richardson TB, et al. Targeting the DNA repair defect in BRCA mutant cells as a therapeutic strategy. Nature. 2005;434:917-21. https:// doi.org/10.1038/nature03445.

6. Tutt AN, Lord CJ, McCabe N, Farmer H, Turner N, Martin NM, et al. Exploiting the DNA repair defect in BRCA mutant cells in the design of new therapeutic strategies for cancer. Cold Spring Harb Symp Quant Biol. 2005;70:139-48. https://doi.org/10.1101/ sqb.2005.70.012.

7. Kristeleit R, Shapiro GI, Burris HA, Oza AM, LoRusso P, Patel MR, et al. A phase I-II study of the oral PARP inhibitor rucaparib in patients with germline BRCA1/2-mutated ovarian carcinoma or other solid tumors. Clin Cancer Res. 2017;23:4095-106. https ://doi.org/10.1158/1078-0432.CCR-16-2796.

8. Swisher EM, Lin KK, Oza AM, Scott CL, Giordano H, Sun J, et al. Rucaparib in relapsed, platinum-sensitive high-grade ovarian carcinoma (ARIEL2 Part 1): an international, multicentre, openlabel, phase 2 trial. Lancet Oncol. 2017;18:75-877. https://doi. org/10.1016/S1470-2045(16)30559-9.

9. Oza AM, Tinker AV, Oaknin A, Shapira-Frommer R, McNeish IA, Swisher EM, et al. Antitumor activity and safety of the PARP inhibitor rucaparib in patients with high-grade ovarian carcinoma and a germline or somatic BRCA1 or BRCA2 mutation: integrated analysis of data from Study 10 and ARIEL2. Gynecol Oncol. 2017;147:267-75. https://doi.org/10.1016/j.ygyno.2017.08.022.

10. Kristeleit RS, Oaknin A, Ray-Coquard I, Leary A, Balmana J, Drew Y, et al. Antitumor activity of the poly(ADP-ribose) polymerase inhibitor rucaparib as monotherapy in patients with platinum-sensitive, relapsed, BRCA-mutated, high-grade ovarian cancer, and an update on safety. Int J Gynecol Cancer. 2019;29:1396-404. https://doi.org/10.1136/ijgc-2019-000623. 
11. Coleman RL, Oza AM, Lorusso D, Aghajanian C, Oaknin A, Dean A, et al. Rucaparib maintenance treatment for recurrent ovarian carcinoma after response to platinum therapy (ARIEL3): a randomised, double-blind, placebo-controlled, phase 3 trial. Lancet. 2017;390:1949-61. https://doi.org/10.1016/s0140 $-6736(17) 32440-6$.

12. Rubraca (rucaparib) tablets [prescribing information]. Boulder, CO: Clovis Oncology, Inc.; 2018. https://www.accessdata .fda.gov/scripts/cder/daf/index.cfm?event=overview.proce ss\&ApplNo=209115. Accessed 7 May 2020.

13. Rubraca (rucaparib) tablets [summary of product characteristics]. Swords, Ireland: Clovis Oncology Ireland Ltd.; 2019. https://www.ema.europa.eu/en/medicines/human/EPAR/rubraca. Accessed 7 May 2020.

14. Cosgrove CM, O'Malley DM. How safe is rucaparib in ovarian cancer? Expert Opin Drug Saf. 2018;17:1249-55. https://doi. org/10.1080/14740338.2018.1550067.

15. LaFargue CJ, Dal Molin GZ, Sood AK, Coleman RL. Exploring and comparing adverse events between PARP inhibitors. Lancet Oncol. 2019;20:e15-e28. https://doi.org/10.1016/S1470 -2045(18)30786-1.

16. Rohr I, Keller M, Chekerov R, Oskay-Oeczelik G, Richter R, Heinrich $\mathrm{M}$ et al. What are the expectations and preferences of patients with ovarian cancer to a maintenance therapy? A NOGGO/ENGOT-OV22 survey (EXPRESSION IV) in 2101 patients. https://congress.esgo.org/media/2017/02/ESGO1 7-Program_in_Word_1.10.17.pdf. Accessed 3 Mar 2020.

17. Drew Y, Ledermann J, Hall G, Rea D, Glasspool R, Highley MS, et al. Phase 2 multicentre trial investigating intermittent and continuous dosing schedules of the poly(ADP-ribose) polymerase inhibitor rucaparib in germline BRCA mutation carriers with advanced ovarian and breast cancer. Br J Cancer. 2016;114:723-30. https://doi.org/10.1038/bjc.2016.41.

18. Balasubramaniam S, Beaver JA, Horton S, Fernandes LL, Tang $\mathrm{S}$, Horne HN, et al. FDA approval summary: rucaparib for the treatment of patients with deleterious BRCA mutation-associated advanced ovarian cancer. Clin Cancer Res. 2017;23:716570. https://doi.org/10.1158/1078-0432.CCR-17-1337.

19. Ledermann JA, Oza AM, Lorusso D, Aghajanian C, Oaknin A, Dean A, et al. Rucaparib for patients with platinum-sensitive, recurrent ovarian carcinoma (ARIEL3): postprogression outcomes and updated safety from a randomised, placebo-controlled, phase 3 trial. Lancet Oncol. 2020;21:710-22. https:// doi.org/10.1016/S1470-2045(20)30061-9.

20. Kristeleit RS, Shapira-Frommer R, Oaknin A, Balmaña J, RayCoquard I, Domchek S, et al. Clinical activity of the poly(ADPribose) polymerase (PARP) inhibitor rucaparib in patients with high-grade ovarian carcinoma and a BRCA mutation: analysis of pooled data from Study 10 (Parts 1, 2a, and 3) and ARIEL2 (Parts 1 and 2). Ann Oncol. 2016;27:abstr 856O. https://doi. org/10.1093/annonc/mdw374.03.

21. Kristeleit R, Oza A, Oaknin A, Aghajanian C, Tinker A, Tredan $\mathrm{O}$, et al. Integrated safety analysis of the poly(ADP-ribose) polymerase (PARP) inhibitor rucaparib in patients (pts) with ovarian cancer in the treatment and maintenance settings. Ann Oncol. 2019;30:abst 1002P. https://doi.org/10.1093/annonc/ $\mathrm{mdz} 250.010$

22. Paolella G, Boyd A, Wirth S, Cuellar S, Venepalli N, Crawford S. Adherence to oral anticancer medications: evolving interprofessional roles and pharmacist workforce considerations. Pharmacy (Basel). 2018;6:23. https://doi.org/10.3390/pharm acy6010023.

23. Ruddy K, Mayer E, Partridge A. Patient adherence and persistence with oral anticancer treatment. CA Cancer J Clin. 2009;59:56-66. https://doi.org/10.3322/caac.20004.
24. Gandhi S, Day L, Paramsothy T, Giotis A, Ford M, Boudreau $\mathrm{A}$, et al. Oral anticancer medication adherence, toxicity reporting, and counseling: a study comparing health care providers and patients. J Oncol Pract. 2015;11:498-504. https://doi. org/10.1200/jop.2015.004572.

25. Burhenn PS, Smudde J. Using tools and technology to promote education and adherence to oral agents for cancer. Clin J Oncol Nurs. 2015;19:53-9. https://doi.org/10.1188/15.S1.CJON.53-59.

26. Ali EE, Chan SSL, Leow JL, Chew L, Yap KY-L. User acceptance of an app-based adherence intervention: perspectives from patients taking oral anticancer medications. J Oncol Pharm Pract. 2019;25:390-7. https://doi.org/10.1177/1078155218778106.

27. Graetz I, McKillop CN, Stepanski E, Vidal GA, Anderson JN, Schwartzberg LS. Use of a web-based app to improve breast cancer symptom management and adherence for aromatase inhibitors: a randomized controlled feasibility trial. J Cancer Surviv. 2018;12:431-40. https://doi.org/10.1007/s11764-018-0682-z.

28. Spoelstra SL, Given CW, Sikorskii A, Coursaris CK, Majum$\operatorname{der}$ A, DeKoekkoek T, et al. Proof of concept of a mobile health short message service text message intervention that promotes adherence to oral anticancer agent medications: a randomized controlled trial. Telemed J E Health. 2016;22:497-506. https:// doi.org/10.1089/tmj.2015.0126.

29. Abrahm J, Blonquist T, Catalano P, Lobach D, Braun I, Halpenny B, et al. Point of care clinical decision support for cancer symptom management: results of a group randomized trial. Support Care Cancer. 2016;24:89-90. https://doi.org/10.1007/s0052 0-016-3209-z.

30. Gustafson DH, DuBenske LL, Atwood AK, Chih M-Y, Johnson RA, McTavish F, et al. Reducing symptom distress in patients with advanced cancer using an e-alert system for caregivers: pooled analysis of two randomized clinical trials. J Med Internet Res. 2017;19:e354. https://doi.org/10.2196/jmir.7466.

31. Basch E, Deal AM, Dueck AC, Scher HI, Kris MG, Hudis C, et al. Overall survival results of a trial assessing patient-reported outcomes for symptom monitoring during routine cancer treatment. JAMA. 2017;318:197-8. https://doi.org/10.1001/jama.2017.7156.

32. Basch E, Deal AM, Kris MG, Scher HI, Hudis CA, Sabbatini $\mathrm{P}$, et al. Symptom monitoring with patient-reported outcomes during routine cancer treatment: a randomized controlled trial. J Clin Oncol. 2016;34:557-65. https://doi.org/10.1200/ jco.2015.63.0830.

33. Zejula (niraparib) capsules [prescribing information]. Waltham, MA: Tesaro, Inc.; 2020. https://www.accessdata.fda.gov/scripts/ cder/daf/index.cfm?event=overview.process \&ApplNo=208447. Accessed 7 May 2020.

34. Zejula (niraparib) capsules [summary of product information]. Waltham, MA: Tesaro, Inc.; 2020. https://www.ema.europa.eu/ en/medicines/human/EPAR/zejula. Accessed 7 May 2020.

35. Lynparza (olaparib) [summary of product information]. Wilmington, DE: AstraZeneca Pharmaceuticals; 2019. https://www.ema. europa.eu/en/medicines/human/EPAR/lynparza. Accessed 7 May 2020.

36. Lynparza (olaparib) tablets [prescribing information]. Wilmington, DE: AstraZeneca Pharmaceuticals; 2019. https://www.acces sdata.fda.gov/scripts/cder/daf/index.cfm?event=overview.proce ss\&ApplNo=208558. Accessed 7 May 2020.

37. Domchek SM, Aghajanian C, Shapira-Frommer R, Schmutzler RK, Audeh MW, Friedlander M, et al. Efficacy and safety of olaparib monotherapy in germline BRCA1/2 mutation carriers with advanced ovarian cancer and three or more lines of prior therapy. Gynecol Oncol. 2016;140:199-203. https://doi. org/10.1016/j.ygyno.2015.12.020.

38. Kaufman B, Shapira-Frommer R, Schmutzler RK, Audeh MW, Friedlander M, Balmaña J, et al. Olaparib monotherapy in patients with advanced cancer and a germline BRCA1/2 
mutation. J Clin Oncol. 2015;33:244-50. https://doi.org/10.1200/ jco.2014.56.2728.

39. Ledermann J, Harter P, Gourley C, Friedlander M, Vergote I, Rustin $\mathrm{G}$, et al. Olaparib maintenance therapy in platinum-sensitive relapsed ovarian cancer. N Engl J Med. 2012;366:1382-92. https ://doi.org/10.1056/NEJMoa1105535.

40. Matulonis UA, Penson RT, Domchek SM, Kaufman B, ShapiraFrommer R, Audeh MW, et al. Olaparib monotherapy in patients with advanced relapsed ovarian cancer and a germline BRCA1/2 mutation: a multistudy analysis of response rates and safety. Ann Oncol. 2016;27:1013-9. https://doi.org/10.1093/annonc/mdw13 3.

41. Mirza MR, Monk BJ, Herrstedt J, Oza AM, Mahner S, Redondo A, et al. Niraparib maintenance therapy in platinum-sensitive, recurrent ovarian cancer. N Engl J Med. 2016;375:2154-64. https ://doi.org/10.1056/NEJMoa1611310.

42. Pujade-Lauraine E, Ledermann JA, Selle F, Gebski V, Penson RT, Oza AM, et al. Olaparib tablets as maintenance therapy in patients with platinum-sensitive, relapsed ovarian cancer and a BRCA1/2 mutation (SOLO2/ENGOT-Ov21): a double-blind, randomised, placebo-controlled, phase 3 trial. Lancet Oncol. 2017;18:1274-84. https://doi.org/10.1016/s1470-2045(17)30469-2.

43. Sandhu SK, Schelman WR, Wilding G, Moreno V, Baird RD, Miranda S, et al. The poly(ADP-ribose) polymerase inhibitor niraparib (MK4827) in BRCA mutation carriers and patients with sporadic cancer: a phase 1 dose-escalation trial. Lancet Oncol. 2013;14:882-92. https://doi.org/10.1016/S1470-2045(13)70240 $-7$.

44. Drew Y, Kristeleit RS, Oaknin A, Ray-Coquard I, Haris NM, Swisher EM. Real-world delivery of rucaparib to patients with ovarian cancer: recommendations based on an integrated safety analysis of ARIEL2 and Study 10. Oncologist. 2020;25:e109e119. https://doi.org/10.1634/theoncologist.2019-0229.

45. Roila F, Molassiotis A, Herrstedt J, Aapro M, Gralla RJ, Bruera E, et al. 2016 MASCC and ESMO guideline update for the prevention of chemotherapy- and radiotherapy-induced nausea and vomiting and of nausea and vomiting in advanced cancer patients. Ann Oncol. 2016;27:v119-v133. https://doi.org/10.1093/annonc/ mdw270.

46. Larkin PJ, Cherny NI, La Carpia D, Guglielmo M, Ostgathe C, Scotte F, et al. Diagnosis, assessment and management of constipation in advanced cancer: ESMO clinical practice guidelines. Ann Oncol. 2018;29:iv111-iv125. https://doi.org/10.1093/annon c/mdy148.

47. Bossi P, Antonuzzo A, Cherny NI, Rosengarten O, Pernot S, Trippa F, et al. Diarrhoea in adult cancer patients: ESMO clinical practice guidelines. Ann Oncol. 2018;29:iv126-iv142. https://doi. org/10.1093/annonc/mdy 145 .

48. National Comprehensive Cancer Network (NCCN) Clinical Practice Guidelines in Oncology. Cancer-related fatigue (Version 1.2020). https://www.nccn.org/professionals/physician_gls/pdf/ fatigue.pdf. Accessed 3 Mar 2020.

49. Wang XS, Woodruff JF. Cancer-related and treatment-related fatigue. Gynecol Oncol. 2015;136:446-52. https://doi. org/10.1016/j.ygyno.2014.10.013.

50. Watters AL, Hansen HJ. Oral/dental oncology. In: Bell RB, Andersen PE, Fernandes R, editors. Oral, head and neck oncology and reconstructive surgery. St. Louis: Elsevier; 2018. p. 341-366.
51. Kikuchi R, Lao Y, Bow DA, Chiou WJ, Andracki ME, Carr RA, et al. Prediction of clinical drug-drug interactions of veliparib (ABT-888) with human renal transporters (OAT1, OAT3, OCT2, MATE1, and MATE2K). J Pharm Sci. 2013;102:4426-32. https ://doi.org/10.1002/jps.23737.

52. McCormick A, Swaisland H. In vitro assessment of the roles of drug transporters in the disposition and drug-drug interaction potential of olaparib. Xenobiotica. 2017;47:903-15. https://doi. org/10.1080/00498254.2016.1241449.

53. Zibetti Dal Molin G, Westin SN, Msaouel P, Gomes LM, Dickens A, Coleman RL. Discrepancy in calculated and measured glomerular filtration rates in patients treated with PARP inhibitors. Int J Gynecol Cancer. 2020;30:89-93. https://doi.org/10.1136/ ijgc-2019-000714.

54. Aapro M, Beguin Y, Bokemeyer C, Dicato M, Gascon P, Glaspy $\mathrm{J}$, et al. Management of anaemia and iron deficiency in patients with cancer: ESMO clinical practice guidelines. Ann Oncol. 2018;29:iv96-iv110. https://doi.org/10.1093/annonc/mdx758.

55. Schiffer CA, Bohlke K, Delaney M, Hume H, Magdalinski AJ, McCullough JJ, et al. Platelet transfusion for patients with cancer: American Society of Clinical Oncology clinical practice guideline update. J Clin Oncol. 2018;36:283-99. https://doi.org/10.1200/ JCO.2017.76.1734.

56. National Comprehensive Cancer Network (NCCN) Clinical Practice Guidelines in Oncology. Hematopoietic growth factors (Version 2.2020). https://www.nccn.org/professionals/physician_gls/ pdf/growthfactors.pdf. Accessed 3 Mar 2020.

57. Oskay-Özcelik G, Alavi S, Richter R, Keller M, Chekerov R, Cecere SC, et al. Expression III: patients' expectations and preferences regarding physician-patient relationship and clinical management-results of the international NOGGO/ENGOTov4-GCIG study in 1830 ovarian cancer patients from European countries. Ann Oncol. 2018;29:910-6. https://doi.org/10.1093/ annonc/mdy037.

58. Fung-Kee-Fung M, Oliver T, Elit L, Hirte HW, Bryson P. Optimal chemotherapy treatment for women with recurrent ovarian cancer. Curr Oncol. 2007;14:195-208. https://doi.org/10.3747/co.v14i5 .135 .

59. Chekerov R, Harter P, Fuxius S, Hanker LC, Woelber L, Müller L, et al. Preference of elderly patients' to oral or intravenous chemotherapy in heavily pre-treated recurrent ovarian cancer: final results of a prospective multicenter trial. Gynecol Oncol Res Pract. 2017;4:6. https://doi.org/10.1186/s40661-017-0040-2.

60. Verbrugghe M, Verhaeghe S, Lauwaert K, Beeckman D, Van Hecke A. Determinants and associated factors influencing medication adherence and persistence to oral anticancer drugs: a systematic review. Cancer Treat Rev. 2013;39:610-21. https://doi. org/10.1016/j.ctrv.2012.12.014.

61. Korach J, Freyer G, Banerjee S, Asher R, Cosin J, Oza A, et al. Long-term tolerability of olaparib tablets as maintenance therapy for platinum-sensitive relapsed ovarian cancer (PSR OC): phase III SOLO2 trial. Ann Oncol. 2018;29:abst 952P. https://doi. org/10.1093/annonc/mdy285.160.

62. Berek JS, Matulonis UA, Peen U, Ghatage P, Mahner S, Redondo A, et al. Safety and dose modification for patients receiving niraparib. Ann Oncol. 2018;29:1784-92. https://doi.org/10.1093/ annonc/mdy 181 . 